\title{
A national, multicenter, non-interventional, observational study on treatment patterns in patients with metastatic renal cell carcinoma in Turkey - NOTES study
}

This article was published in the following Dove Press journal: OncoTargets and Therapy

\section{Șuayib Yalçın,' Ramazan Yildiz, ${ }^{2}$ Faysal Dane, ${ }^{3}$ Aziz Karaoğlu, ${ }^{4}$ Berna Öksüzoğlu, ${ }^{5}$ Özgür Özyılkan, ${ }^{6}$ Alper Sevinç, Feyyaz Özdemir, ${ }^{8}$ Hande Turna, ${ }^{9}$ Rüçhan Uslu, ${ }^{10}$ Esat Ulay"}

'Hacettepe University, Department of Medical Oncology, Ankara, Turkey; ${ }^{2}$ Gazi University, Department of Medical Oncology, Ankara, Turkey; ${ }^{3}$ Marmara University, Department of Medical Oncology, İstanbul, Turkey; ${ }^{4}$ Dokuz Eylül University, Department of Medical Oncology, Izmir, Turkey; ${ }^{5}$ Ankara Oncology Hospital, Clinic of Medical Oncology, Ankara, Turkey; ${ }^{6}$ Bașkent University, Department of Medical Oncology, Ankara, Turkey; ${ }^{7}$ Medical Park Gaziantep Hospital, Medical Oncology Unit, Gaziantep, Turkey; ${ }^{8}$ Karadeniz Technical University, Department of Medical Oncology, Trabzon, Turkey; ' ${ }^{\prime}$ stanbul University, Department of Medical Oncology, İstanbul, Turkey; ${ }^{10} \mathrm{Ege}$ University, Department of Medical Oncology, İzmir, Turkey; "'Novartis Oncology, İstanbul, Turkey

Correspondence: Șuayib Yalçın Department of Medical Oncology, Hacettepe University, School of Medicine, A. Adnan Saygun Street, Samanpazarı 06230, Ankara, Turkey

Tel +90312305 2945

Fax +90 3/2 467 I 3 I3

Email syalcin@hacettepe.edu.tr
Introduction: The introduction of targeted therapies in renal cell carcinoma has significantly improved its prognosis and treatment outcomes in recent years. Such treatment options are targeted therapies of the vascular endothelial growth factor (VEGF) pathway and the mammalian target of the rapamycin pathway. With the use of tyrosine kinase inhibitors (TKIs) and mammalian target of the rapamycin inhibitors, overall survival has increased up to 2 years. In Turkey, due to applicable reimbursement conditions for patients with metastatic renal cell carcinoma (mRCC), interferon use is mandated as a first-line treatment, thus providing information on the use of everolimus only after initial interferon and second-line VEGF-targeted treatments such as VEGF-TKI.

Patients and methods: To provide a first real-life data set in Turkey, we conducted a prospective, non-interventional, observational study and assessed the efficacy and safety of everolimus after two lines of treatment including interferon. A total of 100 patients with histologically confirmed mRCC were enrolled in the study from 11 centers between June 2012 and March 2014 (70 males and 30 females). Efficacy was assessed on the basis of progression-free survival and overall survival; safety of everolimus was assessed on the basis of adverse event occurrence. Results: The study results showed that the median progression-free survival with everolimus treatment was 8.1 months (95\% CI: 5.1-11.1) and the median overall survival was 17.6 months (95\% CI: 10.1-25.1), thus indicating a better overall response based on survival durations than those from the randomized Phase III REnal Cell cancer treatment with Oral RAD001 given Daily study results (4.9 and 14.8 months, respectively).

Conclusion: The study showed that everolimus treatment is a safe and effective treatment option in the treatment of mRCC after VEGF-TKI, with an acceptable safety and tolerability profile in real-life settings.

Keywords: metastatic renal cell carcinoma, mTOR inhibitors, everolimus, observational study, real-life setting, treatment patterns

\section{Introduction}

In Turkey, the latest official figures (2013) show higher rates of renal cancer in men, 7 cases in every 100,000 population, whereas the same rate has been shown to be 3.4 cases/100,000 standardized population in women and there were higher rates of occurrence in the European Union and the USA. ${ }^{1}$ Approximately $90 \%$ of renal cancers are renal cell carcinoma (RCC), and the worldwide incidence of renal cancer has been increasing by $\sim 2 \%-4 \%$ every year for the last two decades. ${ }^{2,3}$ During the 
past two decades, the risk factors for renal cancer such as tobacco smoking, heavy alcohol drinking, hypertension, and obesity showed a rising tendency, which eventually resulted in increasing the risk of malignancy. ${ }^{3}$ Approximately $30 \%$ of all patients with RCC have metastatic disease at presentation, and the available treatments were limited until recently because these cancers are relatively resistant to cytotoxic chemotherapy. ${ }^{4}$ However, the introduction of targeted therapies has significantly improved treatment outcomes for these patients. ${ }^{4-8}$ These therapies either target the vascular endothelial growth factor (VEGF) pathway or the mammalian target of the rapamycin (mTOR) pathway, both of which are related to the pathogenesis of clear cell metastatic RCC (mRCC). ${ }^{6,89}$ With the use of tyrosine kinase inhibitors (TKIs) and mTOR inhibitors, survival up to 2 years became a reachable goal. ${ }^{6}$ mTOR is a serine/threonine kinase of the $\mathrm{PI} 3 \mathrm{~K} / \mathrm{AKT}$ signaling pathway, and stimulation of this pathway results in cell proliferation, growth, protein synthesis, and angiogenesis. mTOR inhibitors block this signaling pathway and improve treatment outcomes in patients with advanced and metastatic renal cancer. ${ }^{8,10}$

Despite the availability of targeted therapies in Turkey, due to mandated governmental reimbursement regulations, first-line treatment requires interferon use, and treatments that target the VEGF pathway are given as second line; therefore, mTOR inhibitors are reserved for third-line treatment. In this prospective, non-interventional, real-life NOTES (a National, multicenter, non-interventional, Observational study on TrEatment patternS in patients with metastatic renal cell carcinoma) study conducted in Turkey, we aimed to generate a database on the use of everolimus in the treatment of mRCC during routine local practice.

\section{Patients and methods}

A multicenter, national, non-interventional, real-life study was conducted in Turkey with 11 participating sites and 100 patients with mRCC who were enrolled between July 2012 and March 2014. Patients aged over 18 years with histologically or cytologically confirmed mRCC were eligible. Other enrollment criteria were presence of measurable disease according to the Response Evaluation Criteria In Solid Tumors criteria, having undergone previous systemic therapy following VEGF-TKI intolerance or disease progression, and providing consent for participation. Patients who were pregnant or lactating or with active hepatitis $\mathrm{B}$ and $\mathrm{C}$ or who were actively participating in a clinical or non-interventional study were excluded.

Patients were followed-up for a period of at least 12 months after enrollment during their treatment with everolimus.
Patients were enrolled in the study only after an occurrence of VEGF-TKI intolerance or progression of disease. The primary objective of the study was to collect information on the mean treatment duration with everolimus and observe the main demographic and clinical profiles of patients with histologically confirmed mRCC. Other parameters of interest included survival, disease progression, treatment patterns (systemic therapies used, required dose changes, and discontinuation of therapy), and treatment toxicity. Overall survival (OS), time to event analysis, disease progression, and treatment toxicity data were analyzed from the onset of first everolimus treatment using Kaplan-Meier survival curves. Statistical analyses were performed using SPSS software, version 18.1 for Windows (IBM Corporation, New York, NY, USA).

\section{Ethics}

The study protocol was reviewed and approved by an independent ethics committee or institutional review board (approval from institutional review board at Kecioren Training and Research Hospital, Turkey, dated April 25, 2012 on files) and met the principles of the Declaration of Helsinki. The study was conducted in accordance with Good Clinical Practice, the principles outlined in the Declaration of Helsinki, and local regulations. All patients provided written informed consent before participation in the study.

\section{Results}

A total of 100 patients ( $70 \%$ males) were included in the study from 11 centers between June 2012 and March 2014. Data collection was terminated on June 9, 2015. The median age of the patients was 55 years (range, 22-78 years) at diagnosis. Histologic confirmations were present for clear cell $(n=86)$ and non-clear cell RCC ( $n=2)$, and data were not confirmed for the rest of the patients $(n=12)$. Sixty-five percent of patients were confirmed as having stage IV disease during enrollment. Details of the demographic and disease characteristics are presented in Table 1.

The median duration of follow-up was 40.5 months (range, 5-164 months); the median OS from the time of diagnosis was 49.3 months and from the first-line systemic treatment was 19.9 months. The median progression-free survival (PFS) and OS with everolimus treatment were 8.1 months (95\% CI: 5.1-11.1) and 17.6 months (95\% CI: 10.1-25.1), respectively.

During the first-line treatment, the majority (84\%) of patients received interferon treatment in line with the local reimbursement conditions, followed by sunitinib, an oral multitargeted kinase inhibitor that inhibits certain receptor 
Table I Demographics and medical history at admission for evaluation

\begin{tabular}{lll}
\hline Characteristics & N & Percentage \\
\hline Sex & 70 & 70.0 \\
Male & 30 & 30.0 \\
Female & 55 & $22-78$ \\
Age (median years, min-max) & Mean & SD \\
\hline BMI & 26.50 & 4.81 \\
\hline BMI (kg/m ${ }^{2}$ ) & $\mathbf{N}$ & Percentage \\
\hline Smoking status & 7 & 7 \\
\hline Current smoker & 33 & 33 \\
Previous smoker & 41 & 41 \\
Never smoked & 19 & 19 \\
Unknown/missing & $\mathbf{N}$ & Percentage \\
\hline Staging at diagnosis (mRCC) & 2 & 2.0 \\
\hline Stage I & 6 & 6.0 \\
Stage 2 & 12 & 12.0 \\
Stage 3 & 65 & 65.0 \\
Stage 4 & 15 & 15.0 \\
Unknown & $\mathbf{N}$ & Percentage \\
\hline Histologic diagnosis & 86 & 86.0 \\
\hline Clear cell carcinoma & 2 & 2.0 \\
Non-clear cell carcinoma & 12 & 12.0 \\
Not identified/not known & $\mathbf{N}$ & \\
\hline Other risk factors present at diagnosis & 20 & \\
\hline Overweight & 12 & \\
Obesity & 3 & \\
Hereditary oncocytoma & $\mathrm{I}$ & \\
Hemodialysis & & \\
\hline Ab & & \\
\hline
\end{tabular}

Abbreviations: BMI, body mass index; mRCC, metastatic renal cell carcinoma.

tyrosine kinases including VEGF receptors (VEGFR type 1, 2 and 3), platelet-derived growth factor receptors (PDGFR- $\alpha$ and PDGFR- $\beta$ ) and c-kit (8\%); pazopanib, a secondgeneration multitargeted TKI against VEGFR-1, -2 , and -3 , PDGFR- $\alpha$, PDGFR- $\beta$, and c-kit (4\%); and sorafenib, an inhibitor of receptor tyrosine kinase involved in angiogenesis (VEGFR-1, -2, and -3, and PDGFR- $\beta$ ) and tumorigenesis (Flt-3, c-Kit, and RET) (3\%). The median duration of interferon use as a first-line treatment was 1.7 months (range, 1-103 months); however, only $27 \%$ of patients continued interferon beyond 3 months. After cessation of interferon therapy, sunitinib was the most frequently used second-line therapy (62\%) and patients had a median duration of treatment with sunitinib of 9.5 months (range, 1-42.6 months). Median duration of treatment with sorafenib and pazopanib as a second-line agent was 5.6 and 5.5 months, respectively. Overall, the median duration of anti-VEGF treatment was 8.8 months (range, 1-66 months). The most common cause of termination of the anti-VEGF treatment was disease progression $(96 \%)$ and intolerance to treatment $(4 \%)$.
Table 2 Survival and response rates with everolimus treatment

\begin{tabular}{ll}
\hline Survival outcomes & Months $\mathbf{( 9 5 \% ~ C l )}$ \\
\hline Median PFS & 8.1 (5.I-II.I) \\
Median OS & $17.6($ I $0.1-25 . I)$ \\
Surviving patients, \% & \\
One-year survival & 58 \\
Two-year survival & $4 I$ \\
Treatment responses with everolimus, \% & \\
CR & 2 \\
PR & 2 \\
Objective response rate (CR + PR) & 4 \\
SD & 42 \\
Disease control rate (CR + PR + SD) & 46 \\
Progression & 22 \\
Unknown response & 32 \\
\hline
\end{tabular}

Abbreviations: $C R$, complete response; OS, overall survival; PFS, progression-free survival; PR, partial response; SD, stable disease.

Everolimus treatment was initiated as a third-line treatment in the majority of patients $(83 \%)$ and the initial dose of everolimus was given as $10 \mathrm{mg} /$ day $(\mathrm{n}=99)$. Patients received everolimus until progression, death, or the end of the follow-up period. Best responses to everolimus treatment were stable disease in $42 \%$, followed by complete response in $2 \%$ and partial response in $2 \%$. The objective response rate and the disease control rate were calculated as $4 \%$ and $46 \%$, respectively. Disease progression was observed in $22 \%$ of patients. No follow-up outcomes were available for $32 \%$ of patients (Table 2).

The median PFS with everolimus treatment was 8.1 months (95\% CI: 5.1-11.1), and the median OS was 17.6 months (95\% CI: 10.1-25.1). One- and 2-year survival rates for everolimus were found as $58 \%$ and $41 \%$, respectively. Effects of achieved responses to previously used medications on PFS and OS following everolimus are presented in Table 3. A significantly longer PFS was observed in patients treated with everolimus who showed longer durations of response with interferon and anti-VEGF agents during the

Table 3 The effect of previous treatments on mPFS and mOS with everolimus

\begin{tabular}{|c|c|c|c|c|c|}
\hline \multirow[t]{2}{*}{ Treatment } & \multirow{2}{*}{$\begin{array}{l}\text { Duration of } \\
\text { response, } \\
\text { months }\end{array}$} & \multicolumn{2}{|c|}{$\begin{array}{l}\text { mPFS with } \\
\text { everolimus }\end{array}$} & \multicolumn{2}{|c|}{$\begin{array}{l}\text { mOS with } \\
\text { everolimus }\end{array}$} \\
\hline & & $\begin{array}{l}\text { Duration } \\
\text { (months) }\end{array}$ & $P$-value & $\begin{array}{l}\text { Duration } \\
\text { (months) }\end{array}$ & $P$-value \\
\hline \multirow[t]{2}{*}{ Interferon } & $<3$ & 6.3 & 0.040 & 12.4 & 0.108 \\
\hline & $\geq 3$ & 9.8 & & 20.7 & \\
\hline Anti-VEGF & $<6$ & 4.2 & 0.015 & 10.7 & 0.716 \\
\hline (any) & $\geq 6$ & 9.8 & & 17.6 & \\
\hline Second-line & $<6$ & 7.8 & 0.120 & 19.0 & 0.951 \\
\hline sunitinib & $\geq 6$ & 9.8 & & 19.9 & \\
\hline
\end{tabular}

Abbreviations: mPFS, median progression-free survival; mOS, median overall survival; VEGF, vascular endothelial growth factor. 


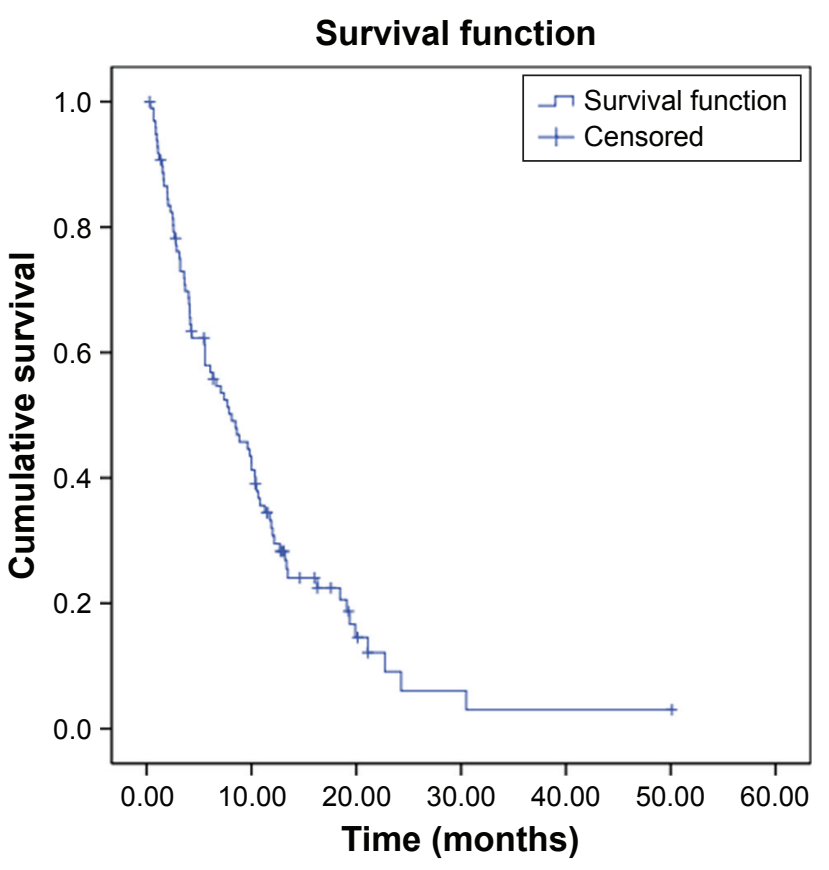

Figure I Progression-free survival with everolimus.

first- and second-line treatments. OS was also longer in these patients, however, not with a statistical significance (Figure 1).

The safety profile of everolimus treatment was mostly related with progression and progression-related deaths. During the follow-up period of patients $\left(-3 \frac{1}{2}\right.$ years, median duration of follow-up: 40.5 months), 59\% had progression of disease. At the end of the follow-up period, $28 \%$ of patients were alive and $8 \%$ of patients were recorded as lost to follow-up.

There were 64 different adverse events recorded, and in 24 cases, the adverse event was evaluated as possibly related to everolimus treatment by the treating physicians (Table 4).

Most frequently reported adverse events ( $5 \%$ or higher), classified into Medical Dictionary for Regulatory Activities (MedDRA) system-organ class in decreasing order were as follows: gastrointestinal disorders: stomatitis (8\%);

Table 4 Adverse events

\begin{tabular}{ll}
\hline Adverse events & Percentage \\
\hline Gastrointestinal disorders & 8 \\
Stomatitis & \\
Respiratory, thoracic, and mediastinal disorders & 8 \\
Pneumonia/pneumonitis & \\
Cardiac disorders & 7 \\
$\begin{array}{l}\text { Cardiopulmonary arrest } \\
\text { General disorders and administrative site conditions }\end{array}$ & 5 \\
Fatigue & \\
\hline
\end{tabular}

respiratory, thoracic, and mediastinal disorders: pneumonia/ pneumonitis (8\%); cardiac disorders: cardiac/cardiopulmonary arrest (7\%); and general disorders and administrative site conditions: fatigue $(5 \%)$.

\section{Discussion}

Everolimus is currently used as a standard treatment for patients who previously progressed on a VEGF-targeted therapy in mRCC. ${ }^{6}$ The results of REnal Cell cancer treatment with Oral RAD001 given Daily (RECORD-1) and REACT studies, which used everolimus, showed that it was well tolerated in patients with $\mathrm{mRCC}$ and was an effective and safe second-line treatment for this progressive and lethal disease. ${ }^{8,10}$ In the pivotal study of RECORD-1, the median PFS was found to be 4.9 months and the median OS was 14.8 months. ${ }^{8}$ The results of our observational study, on the other hand, indicate longer durations with everolimus treatment; the median PFS was 8.1 months and the median OS was 17.6 months.

The results of our study, which collected data in a reallife setting in Turkey, proved a better overall response based on survival times while showing the efficacy of everolimus treatment and presenting an acceptable safety profile. The findings of this study confirm that everolimus is a safe and effective treatment option as a second- and third-line treatment due to the limited therapeutic efficacy of interferon, which is reimbursed as a first-line treatment in Turkey.

Also, in Turkey, due to local reimbursement requirements, mTOR inhibitors can be used only after mandatory first-line treatment with interferon and subsequent anti-VEGF usage in second line. This condition makes mTOR inhibitors as a third-line treatment option in local situation. This paper presents preliminary data of everolimus treatment from a prospective observational study, which is important because it is unique on the basis of its use as a third-line treatment option.

The limitation of this study could be its non-interventional design that resulted in a higher number of lost to follow-up patients, which may have been caused by the nature of routine clinical practice. An additional limitation of the study was the collection of survival data consecutively for first-, second- and third-line treatments. For this reason, survival data are reflected as an OS for RCC. These limitations also might have impacted negatively on the collection of safety profile data. Some adverse events that are related with everolimus use were not recorded as planned. In this study, the most frequently reported adverse event was progression, most probably due to treatment with everolimus at much 
later stages of the disease. On the other hand, stomatitis and pneumonia/pneumonitis were the other two frequent adverse events. However, non-infectious pneumonitis (including interstitial lung disease) is a class effect of rapamycin derivatives, including everolimus, and has been frequently reported in patients taking everolimus. Oral ulcerations and hematologic adverse events were generally expected. Despite term differences, the safety profile was evaluated to be consistent with the available data in this specific patient group.

As a conclusion, this non-interventional, real-life study showed the routine clinical use of everolimus as a third-line treatment in a comparatively sizeable number of patients with mRCC. Favorable efficacy and safety were shown for patients treated with everolimus after at least two previous lines of treatment, the first-line being interferon.

\section{Acknowledgment}

The authors thank Dr Bülent Yalçın, Yıldırım Beyazit University, Clinic of Oncology, Ankara, Turkey and Dr Erdem Özdemir, Novartis Oncology, Istanbul, Turkey for careful review of this article and supporting conduct of this study.

\section{Disclosure}

Dr Esat Ulay is an employee of Novartis. The other authors report no conflicts of interest in this work.

\section{References}

1. Turkish Ministry of Health. Turkish Cancer Statistics (Türkiye Kanser İstatistikleri). Şencan İ, İnce GN, editors. Ankara: Turkish Ministry of Health; 2016.
2. Dhôte R, Pellicer-Coeuret M, Thiounn N, Debré B, Vidal-Trecan G. Risk factors for adult renal cell carcinoma: a systematic review and implications for prevention. BJU Int. 2000;86(1):20-27.

3. Chow WH, Devesa SS, Warren JL, Fraumeni JF Jr. Rising incidence of renal cell cancer in the United States. JAMA. 1999;281(17): $1628-1631$.

4. de Rijke TM, Bellmunt J, Van Poppel H, Marreaud S, Aapro M. EORTC-GU group expert opinion on metastatic renal cell cancer. Eur J Cancer. 2009;45(5):765-773.

5. Escudier B, Eisen T, Stadler WM, et al; TARGET Study Group. Sorafenib in advanced clear-cell renal-cell carcinoma. $N$ Engl J Med. 2007;356(2):125-134.

6. Escudier B, Porta C, Schmidinger M, et al; ESMO Guidelines Committee. Renal cell carcinoma: ESMO clinical practice guidelines for diagnosis, treatment and follow-up. Ann Oncol. 2016;27(Suppl 5): v58-v68.

7. Escudier B, Pluzanska A, Koralewski P, et al; AVOREN Trial investigators. Bevacizumab plus interferon alfa- 2 a for treatment of metastatic renal cell carcinoma: a randomized, double-blind phase III trial. Lancet. 2007;370(9605):2103-2111.

8. Motzer RJ, Escudier B, Oudard S, et al; RECORD-1 Study Group. Phase 3 trial of everolimus for metastatic renal cell carcinoma: final results and analysis of prognostic factors. Cancer. 2010;116(18): 4256-4265.

9. Vivanco I, Sawyers CL. The phosphatidylinositol 3-Kinase AKT pathway in human cancer. Nat Rev Cancer. 2002;2(7):489-501.

10. Grunwald V, Karakiewicz PI, Bavbek SE, et al; REACT Study Group. An international expanded-access program of everolimus: addressing safety and efficacy in patients with metastatic renal cell carcinoma who progress after initial vascular endothelial growth factor receptor-tyrosine kinase inhibitor therapy. Eur J Cancer. 2012;48(3): 324-332.

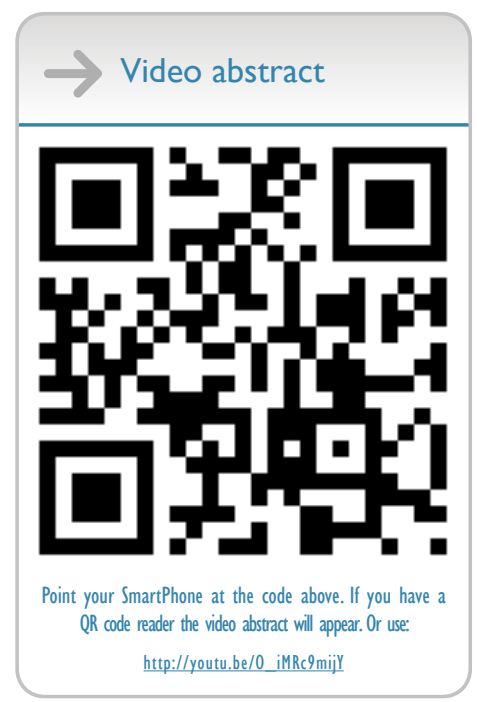




\section{Publish your work in this journal}

OncoTargets and Therapy is an international, peer-reviewed, open access journal focusing on the pathological basis of all cancers, potential targets for therapy and treatment protocols employed to improve the management of cancer patients. The journal also focuses on the impact of management programs and new therapeutic agents and protocols on

patient perspectives such as quality of life, adherence and satisfaction. The manuscript management system is completely online and includes a very quick and fair peer-review system, which is all easy to use. Visit http://www.dovepress.com/testimonials.php to read real quotes from published authors.

Submit your manuscript here: http://www.dovepress.com/oncotargets-and-therapy-journal 